\title{
RISK MEASUREMENT AND EVALUATION IN RFI AND RFP PROCESSES AT BULGARIAN MOBILE NETWORK OPERATORS
}

\author{
Avgustin Milanov 1,a,* \\ ${ }^{1}$ Faculty of Economics, South-West University “Neofit Rilski”, Ivan Mihailov str.60, Blagoevgrad, \\ Bulgaria \\ aavgustin.milanov@gmail.com \\ ${ }^{*}$ Corresponding author
}

Cite as: Milanov, A. (2020). Risk measurement and evaluation in RFI and RFP processes at the Bulgarian mobile telecommunication operators, Ekonomicko-manazerske spektrum, 14(2), 24-35.

Available at: dx.doi.org/10.26552/ems.2020.2.24-35.

Received: 28 May 2020; Received in revised form: 17 July 2020; Accepted: 3 August 2020; Available online: 10 September 2020

\begin{abstract}
The present paper regards some possible approaches for measurement and evaluation of the risk in the "Request for Information" (RFI) and "Request for Proposal" (RFP) processes in the supply chain of Bulgarian mobile ntework operators. These approaches include measurement and calculations of the risk based on the use of risk calculation equation and questionnaire surveys and follow-up score cards. The risk calculation equation proposed in the paper assumes that each risk event or risk action " $m$ " can be regarded as a function of the likelihood of occurrence, the consequences, and the imminence in regard to the time horizon for the occurrence of the very same risk event or risk action " $m$ ". Apart from these components, the risk equation employed also considers the space in which the risk occurs and develops, as well as the extent of the actions taken to prevent and mitigate risk at a certain organizational level. The data collected from the questionnaire surveys and score cards are being processed and turned into a specific set of numeric coefficients that represent the contribution and value of the separate risk components. Methods for defining the thresholds for acceptance of the levels of the risks are also suggested. The paper also discusses several more specific problems in the application of risk measurement and evaluation of the RFI and RFP processes in the supply chain of Bulgarian mobile network operators, such as the use of risk evaluation for the point of time when the forecasts of the major indicators of the RFI and RFP processes suggest a major future decline.
\end{abstract}

Keywords: supply chain management, risk management, risk evaluation, RFI and RFP process, telecommunication operators.

JEL Classification: L93, O18, F47

\section{Introduction}

The present paper discusses several possible approaches for measurement and evaluation of risk in the "Request for Information" (RFI) and "Request for Proposal" (RFP) processes in the supply chain of Bulgarian mobile network operators. These approaches include measurement and calculations of the risk based on the use of risk calculation equation and questionnaire surveys and follow-up score cards. (Acar et al., 2003) The risk calculation 
equation proposed in the paper assumes that each risk event or risk action " $\mathrm{m}$ " can be regarded as a function of the likelihood of occurrence, the consequences, and the imminence in regard to the time horizon for the occurrence of the very same risk event or risk action " $\mathrm{m}$ ". Apart from these components, the risk equation employed also considers the space in which the risk occurs and develops, as well as the extent of actions taken to prevent and mitigate risk at a certain organizational level. (Brinkley and Stone, 1996) The data collected from the questionnaire surveys and score cards are processed and turned into a specific set of numeric coefficients that represent the contribution and value of the separate risk components. Methods for defining the thresholds for acceptance of the levels of the risks are also suggested. The paper also discusses several more specific problems in the application of risk measurement and evaluation of the RFI and RFP processes in supply chain of Bulgarian mobile network operators, such the use of risk evaluation for the point of time when the forecasts of the major indicators of the RFI RFP processes suggest a major future decline. (Brooks, 1994)

\section{Literature review}

The present paper's approach to risk measurement and evaluation, which differs significantly from the one used in traditional financial management, dates to 1989, when it was proposed by R. N. Charrette for the purposes of software engineering risk analysis and management. Charrette proposed to measure risk using the following risk assessment and evaluation equation:

$$
R(m)=L(m) \times C(m) \times I(m)
$$

Where:

$\mathrm{L}(\mathrm{m})$ is the likelihood of occurrence of the risk event or action " $\mathrm{m}$ ";

$\mathrm{C}(\mathrm{m})$ stands for the consequences from the occurrence of the risk event or action " $\mathrm{m}$ ", and

$\mathrm{I}(\mathrm{m})$ is the imminence of the risk event or action " $\mathrm{m}$ " in regards to the time horizon.

The problem of risk measurement and evaluation in RFI and RFP at mobile network operators is a part of the broader problem of measuring risk at the business process level within organizations. (Dragan et al., 2020) All business processes produce certain risks (Reilly et al., 2016) which are usually regarded by managers in terms of technical performance, cost, and schedule. In a more holistic approach, the risks within the organization are also regarded as "business risks". According to a survey conducted by Arthur Anderson and The Economist and cited by Turner and Hunsucker, "business risk" is defined as "the threat that an event or action will adversely affect the organization's ability to achieve its business objectives and execute its strategies effectively" (The Economist). Considering the concept of the "Request for Information" (RFI) and "Request for Proposal" (RFP) processes in the supply chain of mobile network operators as business risks, one can easily apply many of the existing (and financial by nature) methodologies for quantifying and measuring the business risks and their components. Most of these methodologies, however, suffer from one main disadvantage: they present a risk either as a standard deviation of a certain indicator across an average value, or present some understanding of risk components which is not clearly explicit and/or does not include all these very same risk components. (Hayan, 1996) The present paper adapts a particular methodology for measuring occupational health and safety risks in tourism companies by means of numerical risk coefficients and use of risk evaluation score cards. Beside the seminal work or R. N. Charette, this methodology was also thoroughly explained by John V. Turner and John L. Hunsucker in an article named 
"Effective Risk Management: A Global Based Approach", published in the International Journal of Technology Management. It involves the achievements of several US and international research and innovation development programs, such as:

- "SSP" (the Space Shuttle Program);

- "ISSP" (the International Space Station Program);

- "F/A-18" (a project of the US Department of Defense); and

- "AFMC" (the US Air Force Materiel Command).

Later, this methodology was adapted and implemented for the needs of risk management in the innovation process of Bulgarian travel and tourism companies, mainly from the sub-sector of the hotel industry, with regard to risk management in tourism innovation processes and risk management in health and safety in tourism companies. (Juglar, 1862) The model adapted by Dimitrov for risk evaluation and assessment in the hotel industry based on variables of the likelihood ( $\mathrm{Lm})$ of occurrence of a risk event or action " $\mathrm{m}$ ", the consequences $(\mathrm{Cm})$ from the occurrence of the risk event or action " $\mathrm{m}$ ", and imminence $(\mathrm{Im})$ of the risk event or action " $\mathrm{m}$ " in regards to the time horizon was enhanced by A. Hristozova in 2012 for the needs of insurance activities in the travel and tourism industry by adding a component regarding the space of the risk event or action.

$$
R(m)=L(m) \times C(m) \times I(m) \times S(m)
$$

A similar methodology was also presented in 2003 by Dimitar Dimitrov and Erdoan Hadzhiev for the purpose of risk analysis in the working place and in the labor processes in the transport sector. Dimitrov and Hadzhiev's methodology differs from Turner and Hunsucker's concept only in the names of the main variables comprising the risk function and in the scaling of these variables which will be explained further on. They also propose a ready to use questionnaire for the purposes of the transport sector in Bulgaria instead of developing of an Integrated Risk Consequences Scorecard. (Kitchin, 1923)

As for the forecasting part of the present paper, the sources used are related to appearance, concept, and practical implementation of univariate forecasting methods and, more particularly, to those of exponential smoothing forecasting.

The development and usage of univariate and particularly of exponential forecasting methods dates back to the work of R. G. Brown in the 1940s, the results of which were published in 1959. These were further developed and expanded by C. C. Holt in 1957 and Peter Winters in 1960. In 1960s, Pegles (1969) developed the first taxonomy for classification of the exponential smoothing forecasting methods available at that time. In the 1980s, Gardner (Gardner, 1985; 1987) presented some interesting techniques aimed at smoothing of the error residuals in the achieved forecasts. Gardner (1985) and Taylor (2003) also further expanded the opportunities for classifying the exponential smoothing forecasting methods according to the so-called "forecasting profiles" or "forecasting patterns" (see also section 4).

The problem of initialization of variables that are to be used in the exponential smoothing equations was also discussed by numerous authors, such as Ledolter and Abraham (1984) and Hyndman (2014). In 2002, Hyndman, Koehler, Snyder, Grose and later in 2008, Hyndman, Koehler, Ord, and Snyder published their works on the usage of the so-called state-space approach in exponential smoothing.

Over the years, the capacity of univariate and particularly of exponential forecasting methods to produce reliable forecasts was further explored by researchers such as Ledolter and Abraham (1984), Gardner and McKenzie (1985; 1988), Chatfield and Yar (1988), Hamilton (1994), Tashman and Kruk (1996), Delurgio (1998), Williams and Miller (1999), 
Akar et al. (2003), Tsay (2005), Pesaran et al. (2006), Meng, G. and Arunkumar, N. (2019), and many others.

In Bulgaria, until the 1990s only a small portion of univariate forecasting methods (in fact, the simplest ones) and exponential smoothing methods were known, due to weak English language skills of the researchers and an existing preference in the field for multivariate forecasting methods and usage of mainly French and Swedish econometric models. In 1996, Sirakov published a book named Conjuncture and Forecasting of International Markets in which Brown's single exponential smoothing was applied to Bulgarian export of textile production, equipment, and machinery to African countries, mainly Nigeria. This application was however very narrow in scope. A digital publication that tried to promote exponential forecasting smoothing methods in Bulgaria was authored in 2007 by Ivanov from the New Bulgarian University as a part of his business process forecasting course materials. Another attempt at a more explicit explanation and application of exponential forecasting methods in general and the Halt and Halt-Winters method in particular was made in another Mishev and Goev's monograph published in Bulgarian, Statistical Analysis of Time Series (2012). Even there, however, the theoretical presentation of the method was limited and narrowed down to its practical application in certain software packages. In the field of Bulgarian tourism, the published studies on the application of exponential smoothing methods have likewise been limited to a few papers by Dimitrov (2013), Dimitrov et al. (2015) and Dimitrov et al. (2018) dealing with the application of the Halt and Halt-Winters methods for forecasting of the number of tourism arrivals in certain areas and in the country as a whole.

\section{Methodology and the main Results}

For the needs of the present paper's research, and considering the extremely dynamic development of the sector of mobile network operators both globally and in Bulgaria, and the resulting dynamic development of their supply chains, it is necessary to significantly modify the risk assessment and evaluation equation proposed by Charrette, Turner and Hunsucker, Dimitrov and Hristozova. The modification involves adding two more components, two more variables that negatively influence the value of risks within businesses processes. These two components are the extent of actions taken to prevent risk and risk aversion $(\mathrm{P}(\mathrm{m}))$, and the extent of mitigation of consequences of the risks in case they occur. In this regard, the risk assessment and evaluation equation, wherein the variables are calculated based on scorecards, ultimately has the following mathematical notation (3):

$$
R(m)=L(m) \times C(m) \times I(m) \times S(m)-P(m) \times O(m)
$$

This modified risk equation plays a central role in construction of the survey's methodology, the results of which are being reported in the present paper. As for the separate stages of the survey itself, there are seven, as follow: (i) an online questionnaire to be filled in by the employers' two departments involved heavily in the RFI and RFP processes: (ii) a follow-up scorecard survey for each of the components (variables) of risk assessment and the evaluation equation; (iii) calculation of the value of risk in the RFI and RFP processes; (iv) applying of criteria for acceptance or non-acceptance of the business risks connected to RFI and RFP; (v) making of "GO / NO GO decisions" for the usual flow of the RFI and RFP processes; (vi) forecasting the parameters of the usual flow of the RFI and RFP processes; and (vii) anticipating and planning the next measurement, assessment, and evaluation and the "GO / NO GO" decision points. These very same seven stages represent a process not only for measurement, assessment, and evaluation of risks in the RFI and RFP processes in the supply 
chain of one of Bulgarian mobile network operators, but an overall pro-active risk management concept aimed at managing, averting, reducing, and anticipating the respective business risks (Figure 1).

Figure 1: The flow chart of the survey and the suggest risk management concept

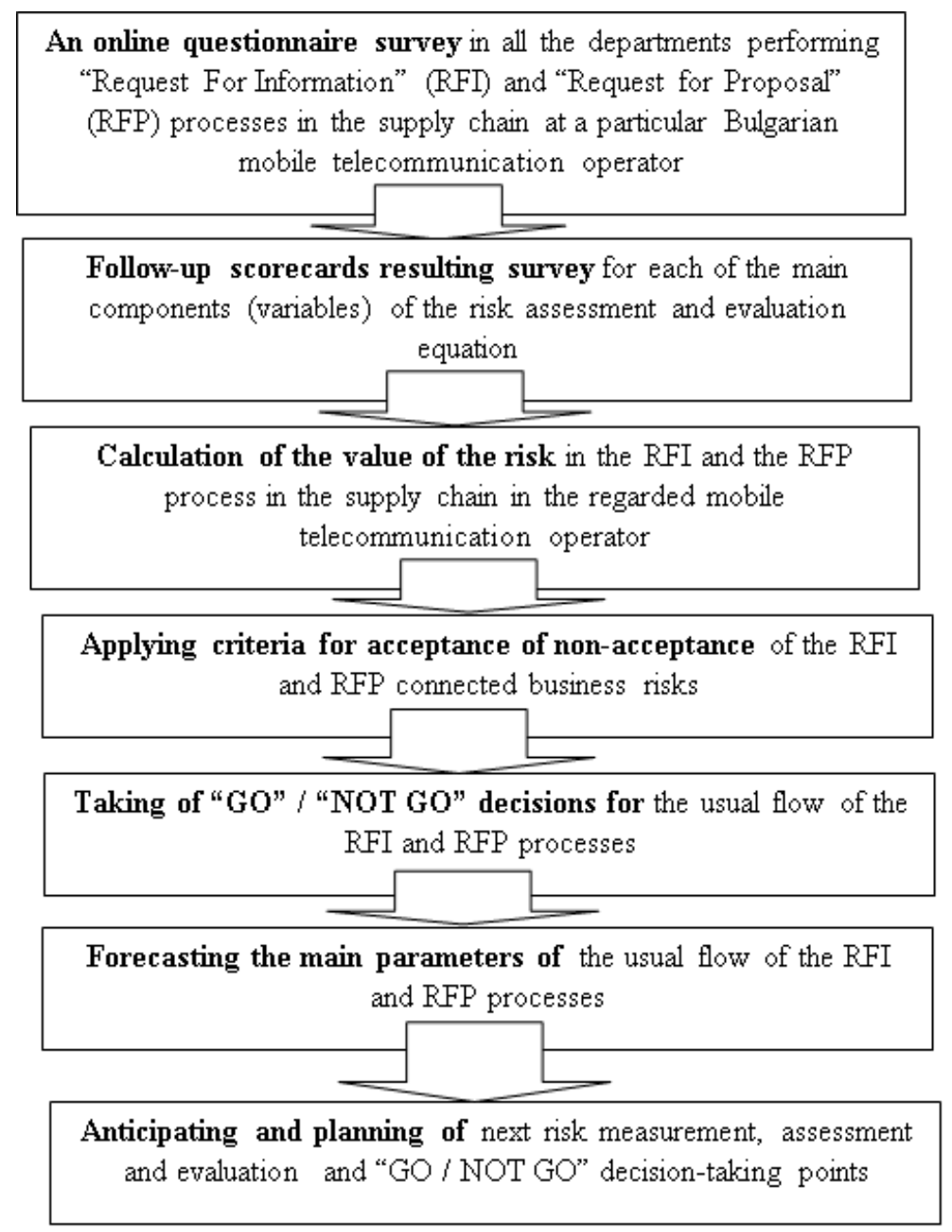

Source: Author's own drawing

The pro-activeness of the suggested risk management concept is the presence of "GO / NO GO" decision points in line with forecasting of the main parameters of the usual flow of the RFI and the RFP processes to anticipate the necessity of the next risk measurement, assessment, and evaluation and the next "GO / NO GO" decision point. It must be pointed out here that this concept assumes the modular approach for risk management in development of new products suggested by R. G. Cooper and R. A. More (Cooper \& More, 1997) and further develops it by adding the forecasting component.

For the performance of risk measurement, assessment, and evaluation stage, an online Google-based questionnaire in Bulgarian language was constructed comprising twenty questions, including a few related to the parameters of the studied population, with the predominant part directly or indirectly related to the variables in risk assessment and the evaluation equation (Figure 2).

The questions directly or indirectly related to the components (variables) of risk assessment and the evaluation equation included the following questions: 
1. How often do you encounter problems in fulfilling a supply contract within the usual two-year period?

2. What is the effect on your department's or company's activities of the problems encountered in executing a delivery contract?

3. How soon after the conclusion of a supply contract do problems appear?

4. If there is a delay in delivery, is it for the following reasons?

5. In case of problems with suppliers, whose activity does the problem that has arisen the most often affect?

6. What is the most common delivery problem?

7. What is the most urgent proposal for change or improvement you would offer to improve supply?

8. Does your direct supervisor provide you with the necessary support or assistance to resolve supply problems?

9. Do the management guidelines provide you with the necessary support or assistance in the event of a supply problem?

10. Does your department have the necessary / sufficient human and expert resources to solve supply problems?

11. Does your department have the necessary / sufficient financial resources?

12. Does your department have the necessary amount of autonomy and authority to resolve supply problems?

Based on the results of the survey and the follow-up scorecard survey, a calculation of the value of business risk / risks can be performed using the risk assessment and evaluation equation:

$$
R(m)=L(m) \times C(m) \times I(m) \times S(m)-(P r(m) \times O v(m)
$$

Where:

Weighted average risk probability coefficient $\mathrm{L}(\mathrm{m})=2.40$

Consequences $\mathrm{C}(\mathrm{m})=4.23$

Time horizon I $(\mathrm{m})=1.499$

Spatial component $\mathrm{S}(\mathrm{m})=8.57$

The risk prevention component $\operatorname{Pr}(\mathrm{m})=3.554$

The risk overcoming component $\mathrm{Ov}(\mathrm{m})=7,883$

The overall risk $(\mathrm{R}(\mathrm{m}))$ calculation achieved by direct substitution in the equation of the variables listed above is as follows:

$$
\begin{aligned}
& \mathrm{R}(\mathrm{m})=\mathrm{L}(\mathrm{m}) * \mathrm{C}(\mathrm{m}) * \mathrm{I}(\mathrm{m}) * \mathrm{~S}(\mathrm{~m})-(\operatorname{Pr}(\mathrm{m}) * \mathrm{Ov}(\mathrm{m}))= \\
& =2.40 * 1.499 * 1.499 * 8.57-3.554 * 7.833=102.4007754 .
\end{aligned}
$$

After the calculations for each of the risk components and each of the risk variables are made, different criteria for acceptance of the occupational health and safety risks can be applied. These include:

- the usage of risk matrices;

- the "f-N" curves; and

- the "ALARP" principle. 
Risk measurement and evaluation in RFI and RFP

processes at Bulgarian mobile network operators Author: Avgustin Milanov

Figure 2: The risk matrix

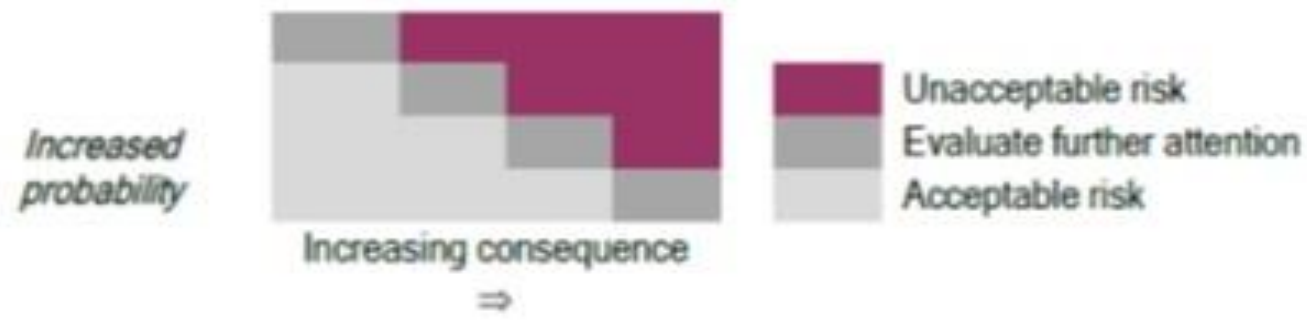

- Unacceptable risk

- Acceptable risk

- A region between acceptable and unacceptable risk, where evaluations have to be carried out in order to determine whether further risk reduction is required or whether more detailed studies should be done first of all.

Source: Norsok Standard (1998) cited by Dimitov, P. (2009)

Figure 3: Matrix-like risk presentation with continuous variables

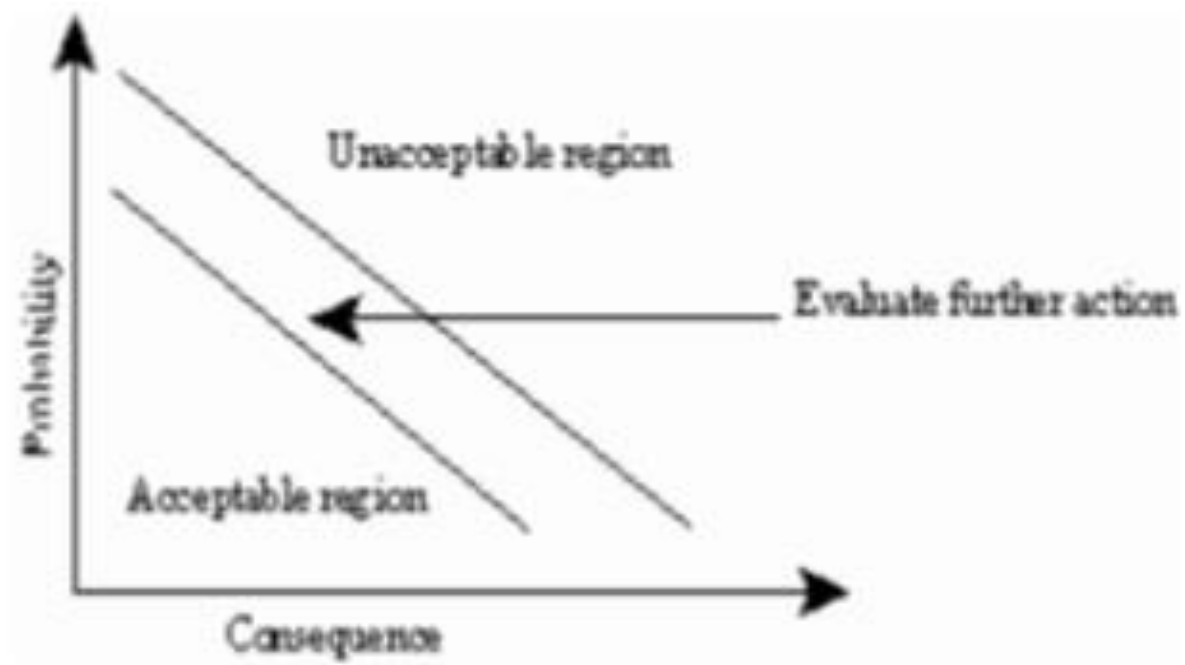

Source: Norsok Standard (1998), cited by Dimitrov, P. (2009) 


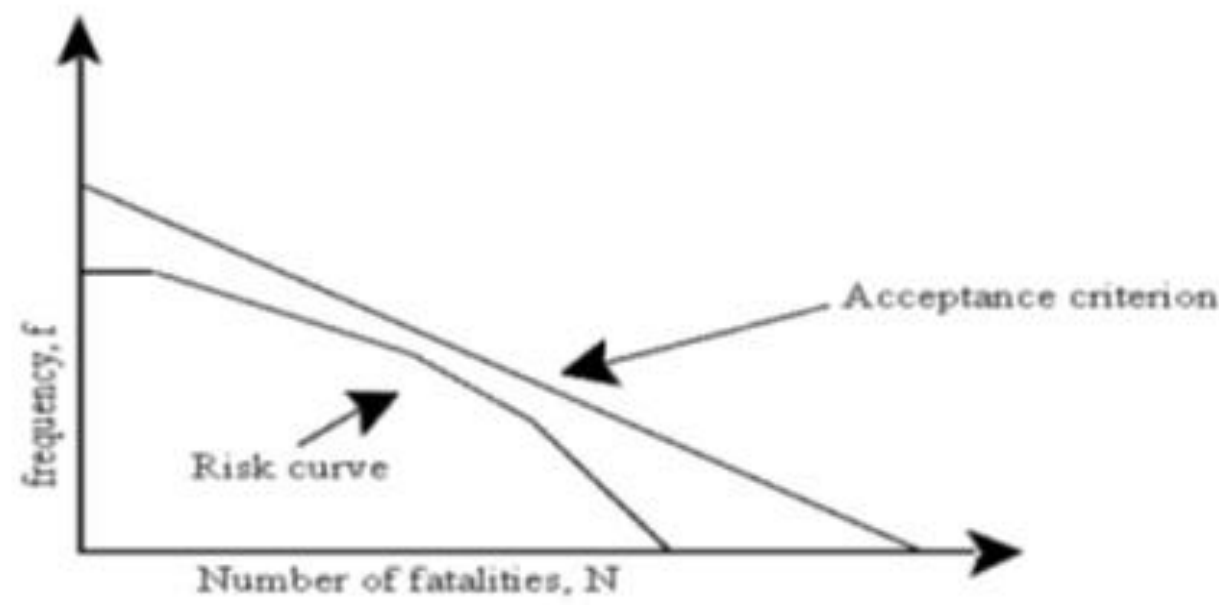

Source: Norsok Standard (1998), cited by Dimitrov, P. (2009)

Figure 5: The ALARP-principle

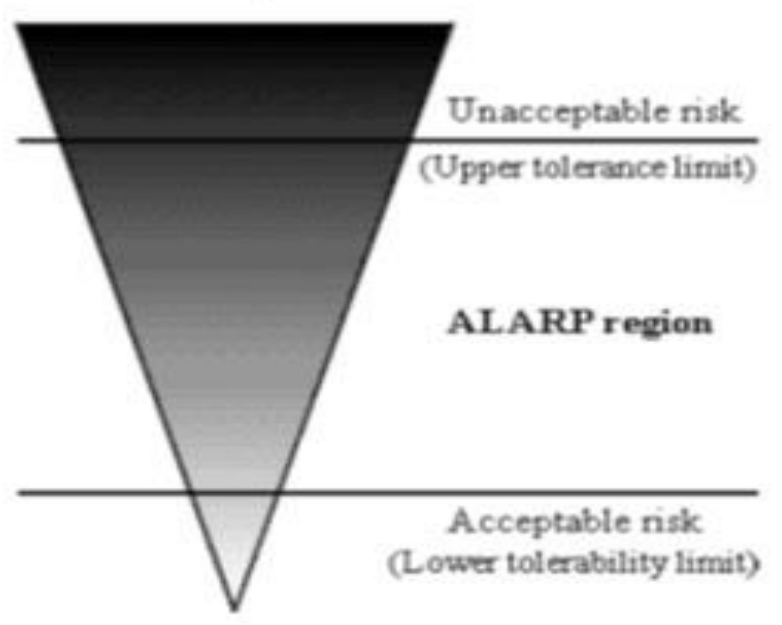

Source: Norsok Standard (1998), cited by Dimitrov, P. (2003, 2006 and 2009)

Using the above criteria, a risk-acceptance level of 100.00 was agreed and preset, so that for the particular risk assessment and evaluation involved, the level of risk was declared unacceptable and correction measures for risk reduction and aversion were implemented.

Forecasting of the basic parameters of the RFI and RFP processes is realized based on the indicators: "number of contracts", "number of contracts with savings", and "number of the issued purchase orders". The forecasting itself is carried out using the Holt-Winters exponentials, smoothing in the presence of additive and multiplicative seasonality, based on the lowest "Stationary R square", "R square", and MAPE values (Figure6, Figure7, Figure8, Figure9, and Figure10): 
Figure 6: Number of contracts - additive cyclicity

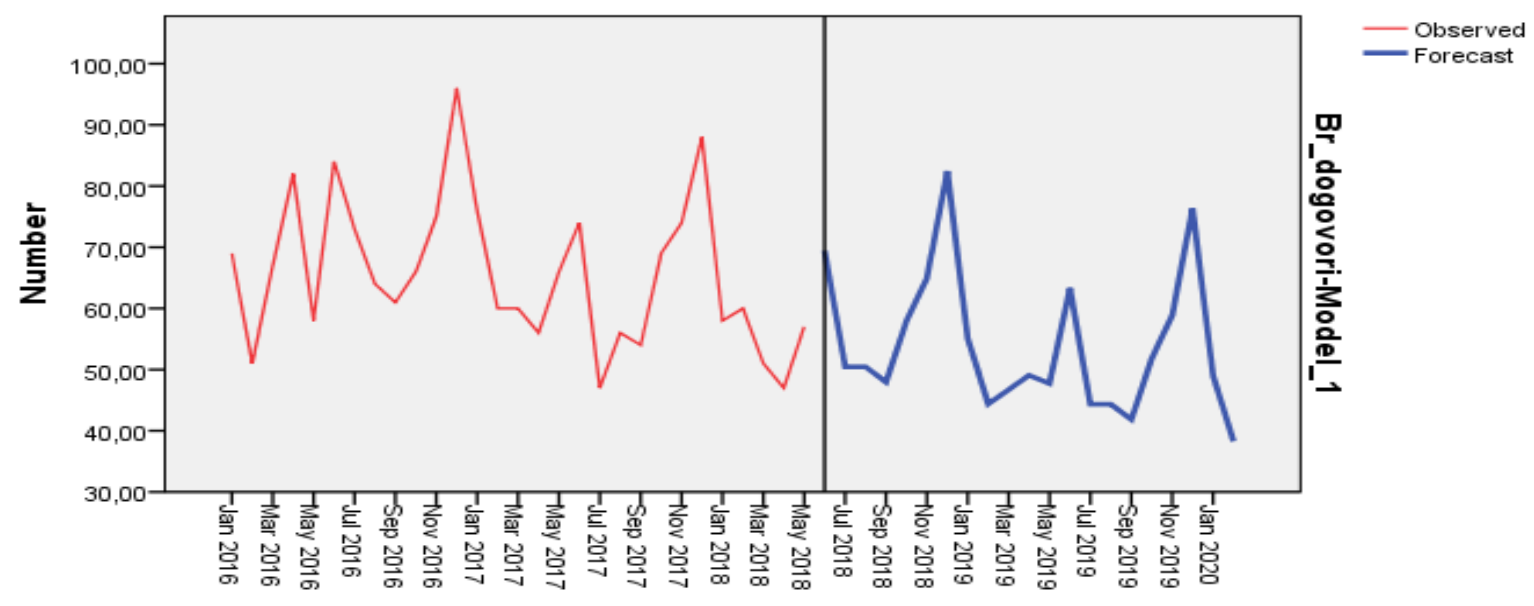

Source: Author's own calculations

Figure 7: Number of contracts - multiplicative cyclicity

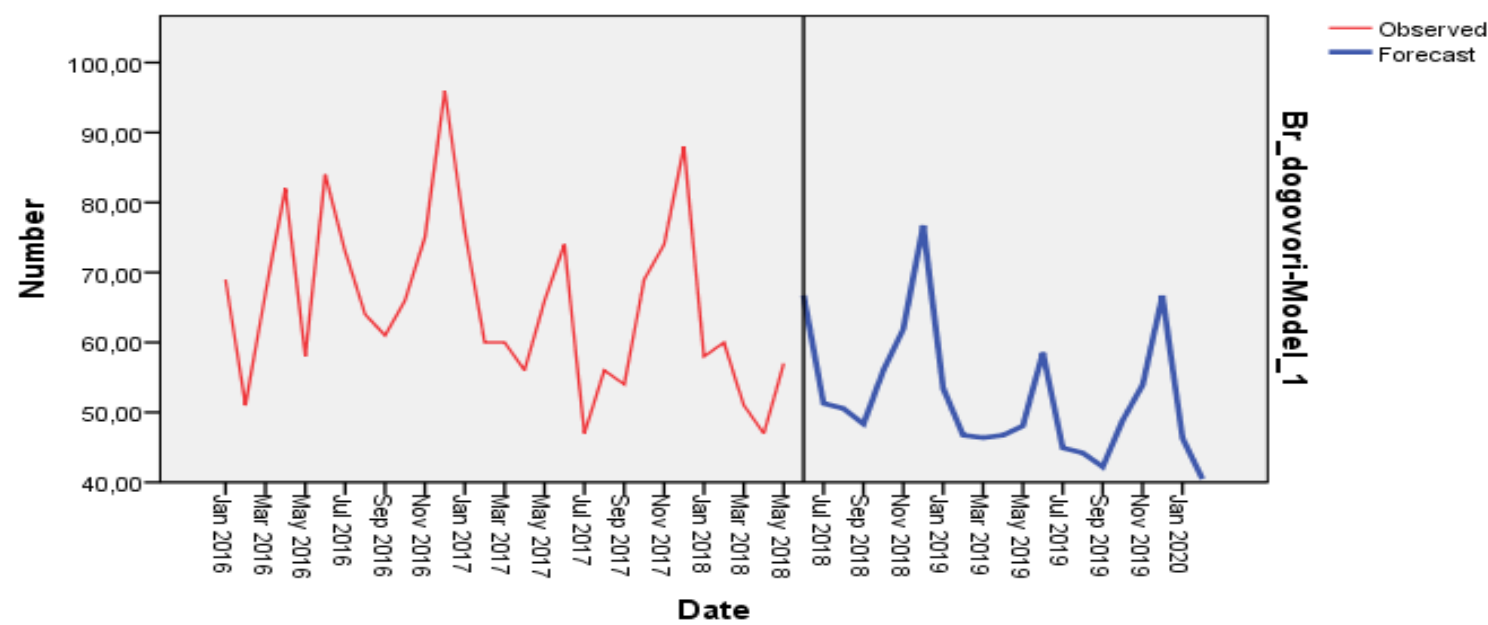

Source: Author's own calculations

Figure 8: Number of issued purchase orders - additive cyclicity

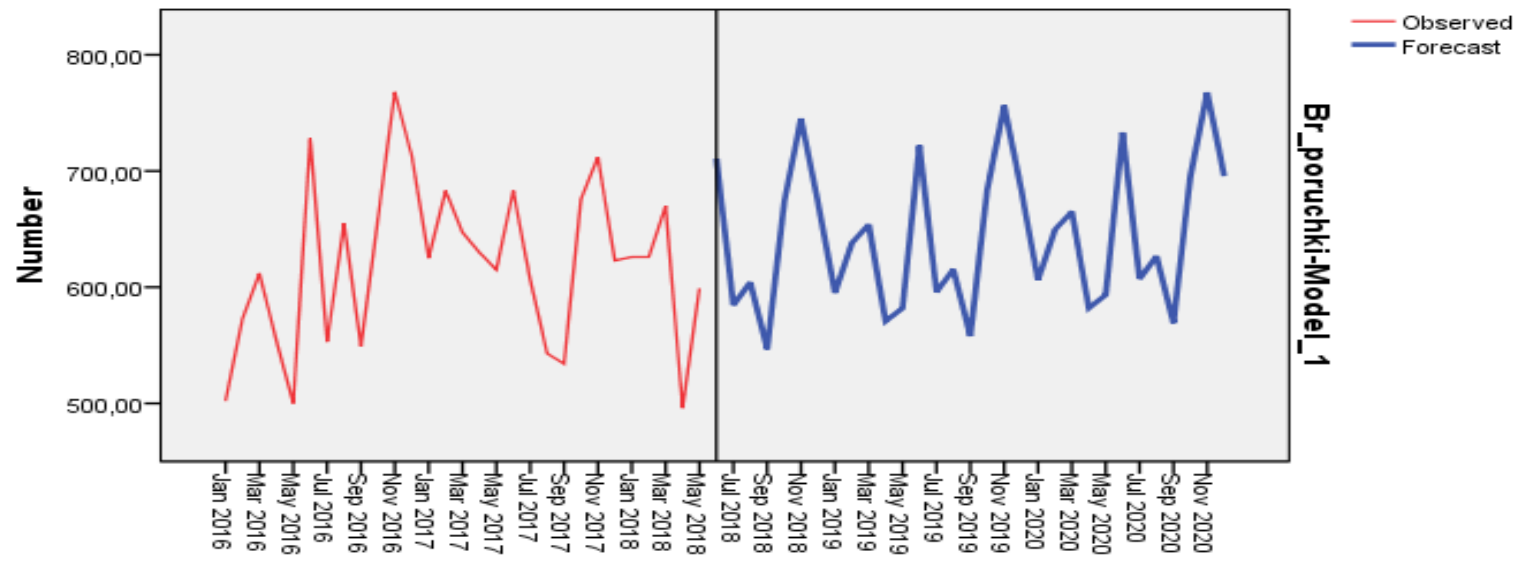

Date

Source: Author's own calculations 
Figure 9: Number of issued purchase orders - multiplicative cyclicity

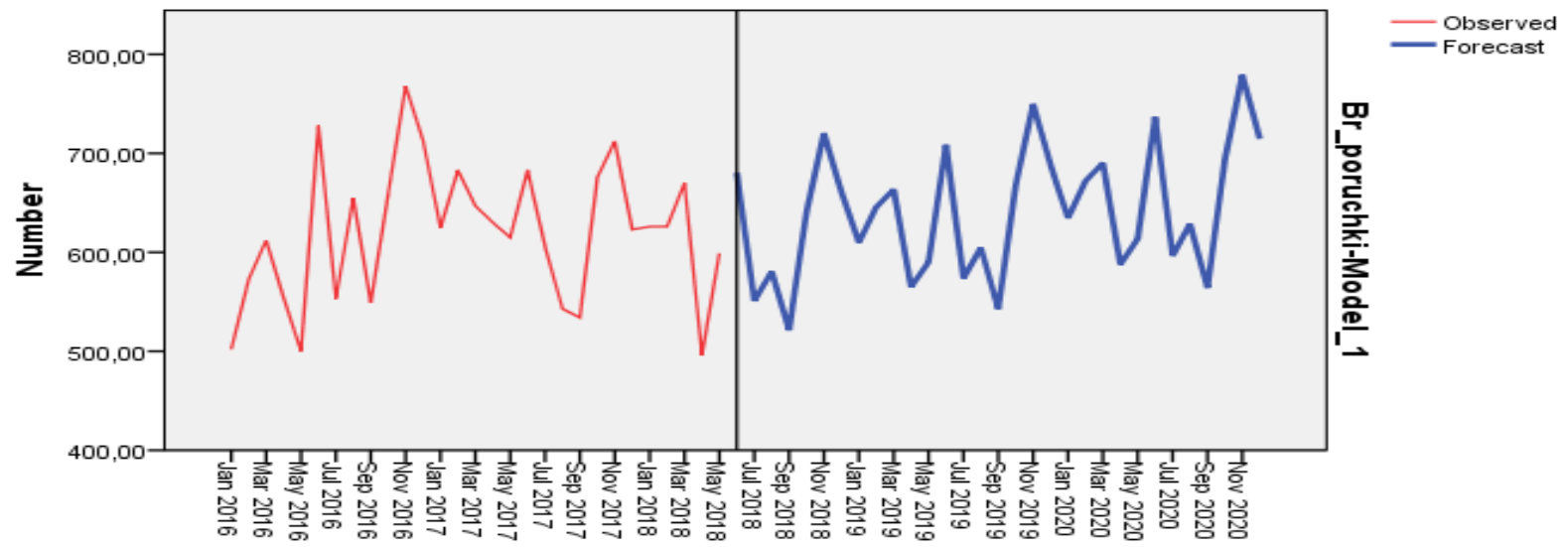

Date

Source: Author's own calculations

Figure 10: Number of contracts with savings - additive cyclicity

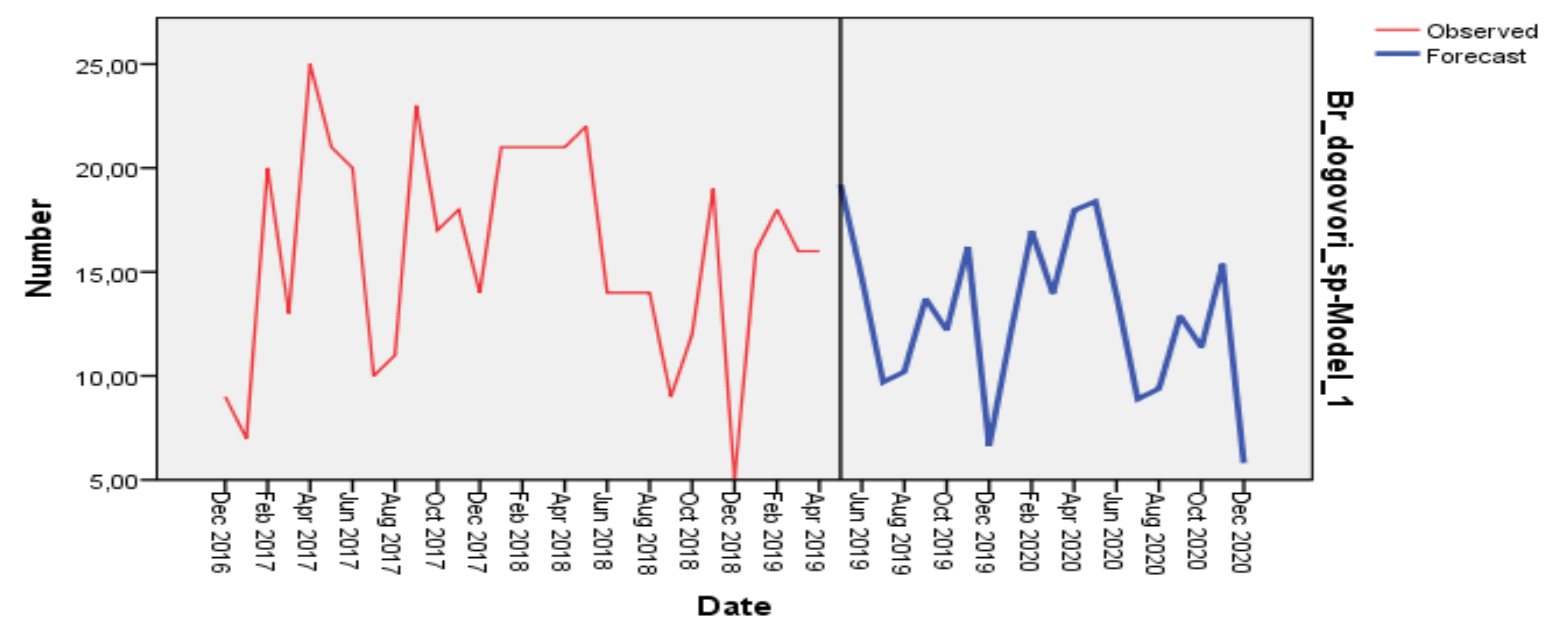

Source: Author's own calculations

Figure 11: Number of contracts with savings - multiplicative cyclicity

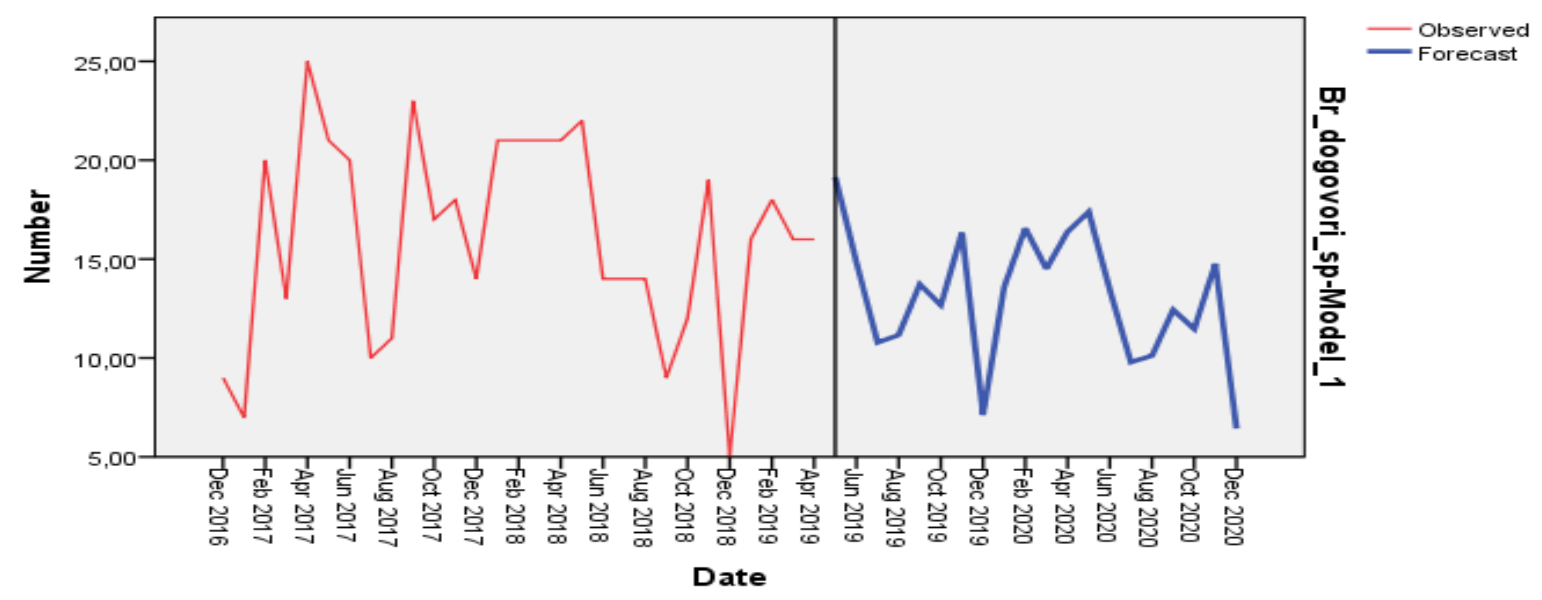

Source: Author's own calculations 
Based to the minimums, should the forecasting curve for the future time period, different choices for the setting of "GO / NO GO" decision points occur.

\section{Discussion and Conclusion}

The presented methodology for risk assessment and evaluation and the overall concept for risk management by means of digital risk evaluation coefficients has led to a significant improvement in the performance of the departments of Bulgarian mobile network operators relation to supply chain management and the RFI and RFP processes. The mere fact of taking into consideration that the rate of everyday business risk may be numerically measured has led to a decrease in the risk level and the "GO / NO GO" decision points have contributed to the improvement of risk reduction, risk aversion, risk transfer, and risk prevention actions in the company. The forecasting of appropriate moments for "GO / NO GO" decision points based on the minimums of the main parameters of the RFI and the RFP processes have also contributed to further refinement of the suggested risk management implementation model.

\section{References}

Acar, W., Keating, R. J., Aupperle, K. E., Hall, W., \& Engdahl, R. (2003). Peering at the past century's corporate strategy through the looking glass of time-series analysis: Extrapolating from chandler's classic mid-century american firms? Journal of Management Studies, 40(5).

Australian Standard AS/NZS 4360:1999 - Risk management.

Brinkley, R., \& Stone, D. (1996). International space station program directive - program risk management emphasis system. ISS-PD-011, NASA, Johnson Space Center, Houston, Texas, USA.

Brooks, W. M. (1994). Project risk management a presentation given at Johnson Space Center. Johnson Space Center, and Huston, Texas, USA.

Brown, R. G. (1959). Statistical forecasting for inventory control. New York: McGraw-Hill.

Charette, R. N. (1989). Software engineering risk analysis and management. New York, USA: Intertext Publications, McGraw-Hill Book Company.

Chatfield, C., \& Yar, M. (1988). Holt-Winters forecasting: Some practical issues. The Statistician, 37, 129-140.

DeLurgio, S. A. (1998). Forecasting principles and applications. Pennsylvania State University: Irwin/McGrawHill.

Dimitrov, D., \& Hadzhiev, E. (2003). Analysis of place of work and labour process risk in transport. Mechanics, Transport, Communication.

Dimitrov, P. (2003). Risk management in tourism innovations. Sofia, Bulgaria: Heron Press.

Dimitrov, P. (2006). Tourism innovations. Blagoevgrad, Bulgaria: "NeofitRilski" University Press.

Dimitrov, P. (2009). Measuring occupational health and safety risks in tourism companies. EgeAkademikBakışDergisi, Turkey.

Dimitrov, P. (2013). Long-run forecasting of the number of the ecotourism arrivals in the municipality of Stambolovo, Bulgaria. Tourism \& Management Studies, 9(1), 41-47.

Dimitrov, P., Kalinova, M., Gantchev, G., \& Nikolov, C. (2015). Exponential forecasting of the monthly volume of the tourism receipts in Bulgaria. Tourism \& Management Studies, 11(1), 104-110.

Dimitrov, P., Daleva, D., \& Stoyanova, M. (2017). Forecasting of the volume of the spa and wellness tourism receipts in the South-West Bulgaria. Journal of Spatial and Organizational Dynamics, 5(2), 83-99.

Dimitrov, P., Krasteva, R., Dimitrov, B., \& Parvanov, P. (2018). Bulgarian tourism and the problem of poverty alleviation in Bulgaria. Tourism \& Management Studies, 14(2), 45-52.

Dragan, D., Keshavarzsaleh, A., Intihar, M., Popovic, V., \& Kramberger, T. (2020). Throughput forecasting of different types of cargo in the Adriatic seaport Koper (Dynamic Factor Analysis-ARIMAX modeling; The principal component regression and Monte Carlo framework were included to identify indicators that are unique to the port.). Maritime Policy \& Management.

Gardner, E. S., \& McKenzie, E. (1985). Forecasting trends in time series. Management Science, 31, 1237-1246.

Gardner, E. S. \& McKenzie, E. (1988). Model identification in exponential smoothing. Journal of the Operational Research Society, 39, 863-867.

Gardner, E. S. (Jun.). (1985). Exponential smoothing: The state of the art. Journal of Forecasting, 4, 1-28. 
Gardner, E. S. (Jun.). (1987). Chapter 11: Smoothing methods for short-term planning and control. The Handbook of Forecasting - A Manager's Guide, (2nd Ed.), New York: John Wiley \& Sons.

Hamilton, J. D. (1994). Time series analysis. Princeton, NJ: Princeton University Press.

Hayan, J. A. (1996). F/A-18 “Risk management plan”. Report MDC 960074, McDonnel Douglas Aerospace, St. Luis, USA.

Holt, C. C. (1957). Forecasting trends and seasonals by exponentially weighted averages. O.N.R. Memorandum 52/1957, Carnegie Institute of Technology.

Hyndman, R. J., Koehler, A. B., Ord, J. K. \& Snyder, R. D. (2008). Forecasting with exponential smoothing The state space approach. Berlin: Springer.

Hyndman, R. J. (2014). Initializing the Holt-Winters method. Hyndsight - A blog by R. J. Hyndeman. Retrieved from June 072016 http://robjhyndman.com/hyndsight/hw-initialization/.

Ivanov, M. (2007). A try and conclusions from the forecasting of the business processes with the help of time series (a MS PowerPoint presentation in Bulgarian language). Retrieved June 07, 2016 from: http://www.nbu.bg/PUBLIC/IMAGES/File/departments/informatics/Izsledvania/Martin_Ivanov_prolet_2007 .pdf.

Juglar, C. (1862). Des Crises commerciales et leur retour périodique en France, en Angleterre, et aux EtatsUnis. Paris: Guillaumin http://gallica.bnf.fr/ark:/12148/bpt6k1060720

Kitchin, J. (1923). Cycles and trends in economic factor. The Review of Economics and Statistics. 5(1), $10-16$.

Ledolter, J., \& Abraham, B. (1984). Some comments on the initialization of exponential smoothing. Journal of Forecasting, 3, 79-84.

Meng, G., \& Arunkumar, N., (2019). Construction of employee training program evaluation system of three exponential forecast based on sliding window. Cluster Computing, 22, 6865-6870.

Mishev, G., \& Goev, V. (2012). Statistical analysis of time series. Sofia, Bulgaria: Avangard-Prima Publishing House.

Norsok Standard (1998). Risk and emergency preparedness analysis. Z-013, Rev.1, March 1998, Annexe "Risk Acceptance Criteria”, Norwegian Technology Standards Institution, Oslo, Norway.

Pesaran, M. H., Pettenuzzo, D., \& Timmermann, A. (2006). Forecasting time series subject to multiple structural breaks. The Review of Economic Studies, 73(4), 1057-1084.

Pegles, C. C. (1969). Exponential forecasting: Some new variations. Management Science, 15(5), 311-315.

Reilly, G., Souder, D., Ranucci, R. (2016). Time horizon of investments in the resource allocation process: Review and framework for next steps. Journal of Management, 42(5), 1169-1194.

Sirakov, S. (1996). Conjuncture and forecasting of international markets. Sofia, Bulgaria: Stoilov Publishing House.

Taylor, J. W. (2003). Exponential smoothing with a damped multiplicative trend. International Journal of Forecasting, 19, 715-725.

The Economist (1996). A Game of risk - the economist survey. Corporate Risk Management.

Tashman, L. J., \& Kruk, J. M. (1996). The use of protocols to select exponential smoothing procedures: A reconsideration of forecasting competitions. International Journal of Forecasting, 12, 235-253.

Tsay, R. S. (2005). Analysis of financial time series. New York: John Wiley \& Sons.

Turner, J. V., \& Hunsucker, J. L. (1999). Effective risk management, a goal-based approach. International Journal of Technology Management, 17(4), 438-458.

Williams, D. W., \& Miller, D. (1999). Level-adjusted exponential smoothing for modeling planned discontinuities. International Journal of Forecasting, 15, 273-289. 